\section{Estudo caso-controle sobre exposição precoce ao leite de vaca e ocorrência de Diabetes Mellitus tipo 1 em Campina Grande, Paraíba}

\section{Case-control study on early exposure to cow's milk and the occurrence of Diabetes Mellitus type 1 in Campina Grande in the State of Paraíba}

Josimar dos Santos Medeiros 1

Maria Amélia Amado Rivera 2

Maria José Cariri Benigna 3

Maria Aparecida Alves Cardoso 4

Maria José de Carvalho Costa 5

\section{Abstract}

Objectives: to study the relationship between early exposure to cow's milk and Diabetes Mellitus, type 1 among children under 18 years old seen at the Hospital Universitário Alcides Carneiro, in Campina Grande.

Methods: case-control study. Sample of 128 individuals of both sexes. Sixty-four mothers with Diabetes Mellitus type 1 and 64 mothers of a control group. Univariate and multivariate analysis was accomplished through logistic and conditional regression.

Results: $84,4 \%$ of diabetic individuals were exposed to cow mild before four months of age while in the control group this percentage was 64,1\%. Univariate analysis determined a significant statistic association between early exposure to cow's milk and Diabetes $(p=0,01)$. In multivariate analysis this association remained and estimated odds ratio was of 4,09 (95\% CI: 14,04; $p=0,01$ ).

Conclusions: results indicate a strong association between children with early exposure to cow's milk and Diabetes Mellitus type 1 events in the population studied. Therefore, children with early exposure to cow's milk have a higher chance of acquiring the disease when compared with those who were exclusively breastfed until at least until four months old.

Key words Diabetes mellitus, Breast feeding, Milk substitutes (Public health)

\section{Resumo}

Objetivos: estudar a relação entre exposição precoce ao leite de vaca e ocorrência de Diabetes Mellitus tipo 1 entre menores de 18 anos atendidos no Hospital Universitário Alcides Carneiro, em Campina Grande.

Métodos: estudo caso-controle. A amostra foi constituída por 128 indivíduos de ambos os sexos. Foram entrevistadas 64 mães de portadores de Diabetes Mellitus e 64 mães de controles. Análises univariadas e multivariadas foram utilizadas.

Resultados: $84,4 \%$ dos indivíduos diabéticos foram expostos ao leite de vaca antes dos quatro meses de idade, enquanto que no grupo controle este percentual foi de $64,1 \%$. A análise univariada identificou uma associação estatisticamente significante entre exposição precoce ao leite de vaca e Diabetes $(p=0,01)$. Na análise multivariada, essa associação permaneceu e a razão chances estimada foi de 4,09 (IC95\%: 1,19-14,04; $p=0,01$ ).

Conclusões: os resultados indicam uma forte associação entre exposição precoce ao leite de vaca e ocorrência de Diabetes Mellitus tipol na população estudada. Assim, crianças expostas precocemente ao leite de vaca apresentam uma chance maior de adquirir a doença quando comparadas àquelas que receberam aleitamento materno exclusivo até pelo menos quatro meses após o nascimento.

Palavras-chave Diabetes mellitus, Aleitamento materno, Substitutos do leite humano 


\section{Introdução}

O Diabetes Mellitus é uma doença sistêmica, metabólica e crônica, causada por deficiência absoluta ou relativa (ação inadequada) de insulina. É muito grave e bastante difundida, com morbidade e mortalidade significativas. Suas complicações agudas são: hiperglicemia, cetose e cetoacidose diabéticas. As complicações crônicas ocorrem como resultado da lesão progressiva de vários órgãos, e incluem a retinopatia, nefropatia, neuropatia, artropatia, doença arterial coronariana, doença cardiovascular e acidente vascular cerebral.

A importância do Diabetes Mellitus, enquanto causa de doença e morte, além da demanda por hospitalização de alto custo, invalidez precoce, incapacidade para o trabalho e deterioração da qualidade de vida, permite situá-la como um grave problema de saúde pública no Brasil.2,3

O Diabetes Mellitus classifica-se em tipo 1 e tipo 2; o segundo tipo costuma aparecer após os 40 anos e é responsável por cerca de $90 \%$ de todos os casos de diabetes. Diversos fatores contribuem para o seu aparecimento, muitos deles perfeitamente evitáveis com a utilização de medidas preventivas, visto que neste caso há uma falência gradual da produção de insulina pelo organismo ou mesmo uma resistência à insulina produzida. Já no diabetes tipo 1, o organismo do paciente deixa de produzir insulina, e sua reposição é essencial para a sobrevivência do paciente. $3-5$

Recentes estudos têm mostrado que os fatores ambientais ocupam um lugar de destaque no aparecimento do Diabetes Mellitus tipo 1, cuja etiologia esteve tradicionalmente vinculada a fatores genéticos, com escassas possibilidades de se prevenir o seu surgimento. Esses estudos procuram mostrar que, com os novos conhecimentos acerca da patogênese do diabetes tipo 1, pode ser possível prevenir seu surgimento, além de ser possível reduzir substancialmente seus efeitos deletérios naqueles que já são portadores dessa doença. ${ }^{4-6}$

Evidências de estudos epidemiológicos e experimentais sugerem que a dieta pode ser importante na etiopatogenia do Diabetes Mellitus tipo 1.7-9 Desde 1984, vários trabalhos têm sugerido que o leite materno seria um fator de proteção para essa doença; esse efeito se daria devido às propriedades anti-infecciosas desse tipo de leite, ou pelo fato de que a amamentação ao seio evitaria que as crianças pudessem ser precocemente expostas a outros agentes etiológicos contidos nos substitutos do leite materno.10-13

Em 1996 alguns pesquisadores observaram, entre os diabéticos, altas concentrações de anticorpos anti-albumina bovina. ${ }^{14}$ Eles postularam a hipótese de que a albumina bovina poderia atuar como desencadeadora do processo destrutivo das células $\beta$ do pâncreas e, conseqüentemente, do diabetes. Resultados conflitantes foram observados nas publicações que se sucederam a essa. ${ }^{15}$

Nesta perspectiva, este trabalho se propõe a avaliar a relação existente entre o consumo precoce de leite de vaca (consumo de fórmulas à base de leite de vaca durante os primeiros quatro meses de idade, em substituição total ou parcial ao leite materno) e o aparecimento do Diabetes Mellitus tipo $1 \mathrm{em}$ pacientes diabéticos de Campina Grande.

\section{Métodos}

O estudo realizado foi do tipo caso-controle. A amostra foi constituída por 128 indivíduos de ambos os sexos, dos quais 64 eram portadores de Diabetes Mellitus tipo 1 (casos) e 64 indivíduos eram normais (controles). Os casos selecionados foram todos os diabéticos tipo 1 menores de 18 anos atendidos no ambulatório de endocrinologia do Hospital Universitário Alcides Carneiro da Universidade Federal da Paraíba, Campus II, em Campina Grande, Brasil, durante o ano de 1999. Os casos foram selecionados utilizando-se os seguintes critérios de inclusão: indivíduos de ambos os sexos portadores de Diabetes Mellitus tipo 1, com idade igual ou inferior a 18 anos na época do diagnóstico definitivo da doença, com residência em Campina Grande e possibilidade de participação da mãe (natural) durante a entrevista. O grupo controle foi selecionado entre os vizinhos dos pacientes e emparelhados por idade, sexo e cor. $\mathrm{O}$ instrumento utilizado para coleta de dados foi um formulário adaptado de Barros e Victora. ${ }^{16} \mathrm{O}$ formulário foi testado, revisado e aperfeiçoado. A entrevista foi realizada com as mães dos pacientes e dos controles, que deram consentimento para participação na pesquisa. O formulário foi aplicado por um dos autores da pesquisa, que estava ciente do grupo a que a mãe dos participantes pertencia; portanto, para se evitar tendenciosidades na aferição das variáveis em estudo, o mesmo foi composto por 23 questões fechadas. Todos os cuidados foram tomados para que não houvesse diferença na abordagem de mães de casos e controles de modo a garantir a fidedignidade e evitar vícios de informação que pudessem comprometer a validade dos resultados. 16

Foram realizadas entrevistas com as mães de todos os indivíduos estudados para levantar dados relacionados com a identificação dos pacientes e seus pais, incluindo idade, cor, renda familiar e escolari- 
dade materna. Foram também obtidas informações sobre antecedentes familiares, enfatizando história familiar de Diabetes Mellitus (tipos 1 ou 2), número de gestações da mãe, peso ao nascer e tipo de parto. A exposição precoce ao leite de vaca foi avaliada por meio da variável relativa à duração do aleitamento materno exclusivo em dias. Foram considerados expostos todos os indivíduos que consumiram leite de vaca antes dos quatro meses de idade. Com relação à história familiar de diabetes, foi verificado se os indivíduos estudados tinham qualquer parente em primeiro grau portador da doença.

Os dados foram processados utilizando-se o software Epi-info versão 6.04b. As análises univariadas e multivariadas, ajustando-se por escolaridade materna, renda familiar e peso ao nascer, e história fa- miliar de Diabetes Mellitus, foram realizadas usando-se modelos de regressão logística condicional por meio do software Stata, versão 7.0.

\section{Resultados}

As principais características dos grupos de estudo estão expressas na Tabela 1. O número de indivíduos em cada sexo, no grupo de diabéticos, foi: 31 para o sexo masculino e 33 para o sexo feminino.

A maior parte dos indivíduos do grupo de casos era de cor branca $(75 \%, n=48)$ e apenas $25 \%(n=16)$ declararam-se como pardos. Proporções semelhantes foram encontradas nos controles (Tabela 1).

Tabela 1

Características gerais dos indivíduos estudados.

\begin{tabular}{|c|c|c|c|c|c|c|c|c|c|c|}
\hline & \multicolumn{4}{|c|}{ Sexo } & \multicolumn{4}{|c|}{ Cor } & \multirow{3}{*}{$\begin{array}{c}\begin{array}{c}\text { Idade atual } \\
\text { (anos) }\end{array} \\
\bar{X} \pm d p\end{array}$} & \multirow{3}{*}{$\begin{array}{c}\begin{array}{c}\text { Renda } \\
\text { familiar* }\end{array} \\
\bar{X}_{ \pm} d p\end{array}$} \\
\hline & \multicolumn{2}{|c|}{ Masculino } & \multicolumn{2}{|c|}{ Feminino } & \multicolumn{2}{|c|}{ Branca } & \multicolumn{2}{|c|}{ Parda } & & \\
\hline & $\mathrm{n}$ & $\%$ & $\mathrm{n}$ & $\%$ & $\mathrm{n}$ & $\%$ & $\mathrm{n}$ & $\%$ & & \\
\hline Diabéticos $(n=64)$ & 31 & 48,0 & 33 & 52,0 & 48 & 75,0 & 16 & 25,0 & $17,6 \pm 6,2$ & $3,4 \pm 1,8$ \\
\hline Controle $(n=64)$ & 31 & 48,0 & 33 & 52,0 & 49 & 77,0 & 15 & 23,0 & $17,3 \pm 5,8$ & $3,7 \pm 1,5$ \\
\hline
\end{tabular}

* Expressa em número de salários-mínimos.

A idade materna (Tabela 2), não revelou diferença significativa entre o grupo de casos (média de 23,4 anos) e o grupo de controles (média de 24,2 anos). Da mesma forma, o peso da criança ao nascer não mostrou diferenças entre os dois grupos (média de $3,53 \mathrm{~kg}$ para o grupo de diabéticos e $3,45 \mathrm{~kg}$ para o grupo controle).

\begin{tabular}{|c|c|c|c|c|c|c|c|c|}
\hline & \multirow{2}{*}{$\begin{array}{c}\text { Peso ao nascer } \\
\text { (kg) }\end{array}$} & \multirow{2}{*}{$\begin{array}{l}\text { Idade materna } \\
\text { (anos)* }\end{array}$} & \multicolumn{6}{|c|}{ Número de gestações* * } \\
\hline & & & \multicolumn{2}{|c|}{1} & \multicolumn{2}{|c|}{2} & \multicolumn{2}{|c|}{$\geq 3$} \\
\hline & $\bar{X} \pm d p$ & $\bar{X} \pm d p$ & $\mathrm{n}$ & $\%$ & $\mathrm{n}$ & $\%$ & $\mathrm{n}$ & $\%$ \\
\hline Diabéticos $(n=64)$ & $3,53 \pm 0,32$ & $23,4 \pm 4,5$ & 42 & 65,6 & 9 & 14,1 & 13 & 20,3 \\
\hline Controle $(n=64)$ & $3,45 \pm 0,30$ & $24,2 \pm 3,8$ & 27 & 42,2 & 18 & 28,1 & 19 & 29,7 \\
\hline
\end{tabular}

* Na época do nascimento do indivíduo participante da pesquisa, * A Até o nascimento do indivíduo participante da pesquisa 
Como pode ser observado ainda na Tabela 2, o grupo de diabéticos teve uma maior porcentagem de mães primíparas $(65,6 \%)$ do que o grupo controle
$(42,2 \%)$. A Figura 1 apresenta a distribuição das mães, em ambos os grupos, segundo a escolaridade.

Figura 1

Distribuição dos indivíduos segundo os anos de estudo das mães.

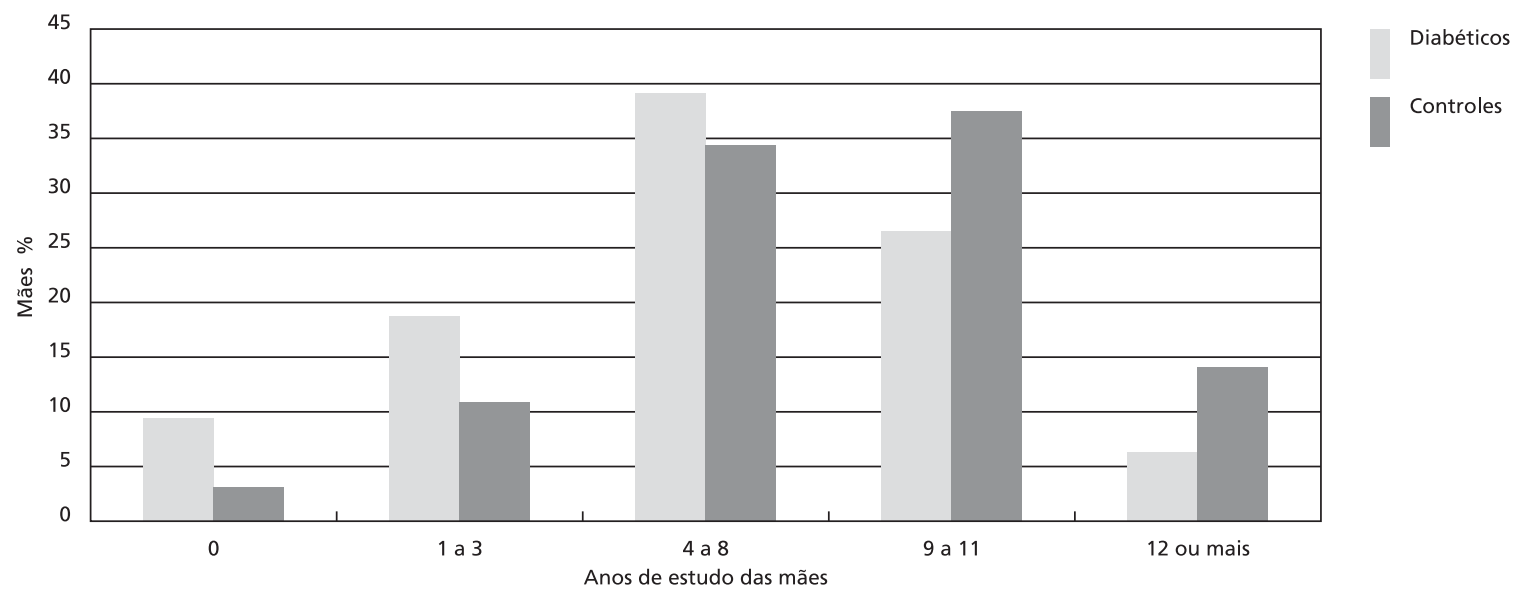

A distribuição difere conforme as categorias anos de estudo difere $(\mathrm{p}<0,01)$ sendo maior na faixa etária dos quatro a oito anos.

Observa-se, na Figura 1, que comparada ao grupo controle, a distribuição do tempo de escolaridade das mães do grupo de casos tende a aumentar nos primeiros anos, alcançando maior proporção na categoria quatro a oito anos de estudo $(39,1 \%, \mathrm{n}=$ 25). A partir dos nove a 11 anos essa tendência se inverte; a maior concentração de mães de indivíduos do grupo controle está na categoria nove a 11 anos de estudo $(37,5 \%, \mathrm{n}=24)$, alcançando também uma proporção considerável $(14,1 \%, \mathrm{n}=9)$ na categoria doze ou mais anos de estudo.

Observa-se na Tabela 3 que a idade média encontrada para a eclosão da doença foi de $9,1 \pm 4,8$ anos e que houve uma associação positiva entre história familiar de Diabetes Mellitus e surgimento de diabetes tipo 1, com uma razão de chances de 2,22 (IC95\%: 1,01 - 4,92). 
Características relacionadas à época do diagnóstico da doença e história familiar de diabetes.

\begin{tabular}{|c|c|c|c|c|c|}
\hline & \multirow{2}{*}{$\begin{array}{l}\text { Idade à época do diagnóstico de diabetes } \\
\text { (anos) }\end{array}$} & \multicolumn{4}{|c|}{ História familiar de diabetes* } \\
\hline & & \multicolumn{2}{|c|}{ Positiva } & \multicolumn{2}{|c|}{ Negativa } \\
\hline & $\bar{X} \pm d p$ & $\mathrm{n}$ & $\%$ & $\mathrm{n}$ & $\%$ \\
\hline Diabéticos $(n=64)$ & $9,1 \pm 4,8$ & 31 & 48,4 & 33 & 51,6 \\
\hline Controle $(n=64)$ & - & 19 & 29,7 & 45 & 70,3 \\
\hline
\end{tabular}

* Odds ratio $=2,22 ; \mathrm{IC} 95 \%: 1,01-4,92 ; \mathrm{p}<0,05)$ entre diabéticos e controles

A Tabela 4 mostra que, no grupo de diabéticos, a mediana da amamentação complementada foi de 62,6 dias e no grupo controle de 98,4 dias, enquanto no grupo dos diabéticos a mediana da amamentação materna exclusiva ficou em 46,5 dias para os diabéticos e 75,1 dias para os grupos controles. Na Tabela 5 verifica-se que a porcentagem da amamentação ma- terna exclusiva foi de $15,6 \%$ e $35,9 \%$ para os grupos de diabéticos e controles, respectivamente.

Verifica-se ainda que, do grupo de pacientes diabéticos, $84,4 \%$ foram expostos ao leite de vaca antes dos quatro meses de idade, enquanto que no grupo controle este percentual foi de $64,1 \%$ (OR $=3,03$ (IC95\%: 1,21-7,72)

Características do aleitamento materno exclusivo e do aleitamento materno complementado na alimentação dos indivíduos estudados.

\begin{tabular}{lcccc}
\hline & \multicolumn{2}{c}{$\begin{array}{c}\text { Aleitamento materno exclusivo } \\
\text { (dias) }\end{array}$} & \multicolumn{2}{c}{$\begin{array}{c}\text { Aleitamento materno + Leite de } \\
\text { vaca* (dias) }\end{array}$} \\
\cline { 2 - 5 } & $\bar{X} \pm d p$ & Mediana & $\bar{X} \pm$ dp & Mediana \\
\hline Diabéticos $(n=64)$ & $55,5 \pm 48,3$ & 46,5 & $76,1 \pm 55,9$ & 62,6 \\
Controle $(n=64)$ & $81,1 \pm 40,2$ & 75,1 & $103,1 \pm 67,4$ & 98,4 \\
\hline
\end{tabular}

* Ou aleitamento materno complementado

Comparação entre o tempo de exposição precoce ao leite de vaca nos grupos estudados.

\begin{tabular}{|c|c|c|c|c|}
\hline & \multicolumn{2}{|c|}{$\begin{array}{l}\text { Grupo de diabéticos } \\
\qquad(n=64)\end{array}$} & \multicolumn{2}{|c|}{$\begin{array}{l}\text { Grupo controle } \\
\qquad(n=64)\end{array}$} \\
\hline & $\mathrm{n}$ & $\%$ & $\mathrm{n}$ & $\%$ \\
\hline Aleitamento materno exclusivo $\geq 4$ meses & 10 & 15,6 & 23 & 35,9 \\
\hline Exposição precoce ao leite de vaca ** $<4$ meses & $54 *$ & 84,4 & 41 * & 64,1 \\
\hline Total & 64 & 100,0 & 64 & 100,0 \\
\hline
\end{tabular}

* $\left(\chi^{2}=5,9 ; p=0,01\right)$, * Odds ratio $=3,03($ IC95\%: 1,21 - 7,72; $p=0,01)$ entre diabéticos e controles 
A Tabela 6 apresenta o resultado da análise de regressão logística condicional onde o efeito da introdução de leite de vaca precocemente é ajustado pelas variáveis escolaridade materna, renda, peso ao nascer e história familiar de diabetes.

Conforme pode ser observado na Figura 4, os diabéticos comparados com os controles tiveram um pi- co na freqüência de introdução de leite de vaca na alimentação por volta do $30^{\circ}$ dia de vida $(26,6 \%, \mathrm{n}=$ $17, \mathrm{p}<0,05)$, com um pico menor, mas significativo, também no terceiro dia $(12,5 \%, \mathrm{n}=8, \mathrm{p}<0,05)$. Já o grupo controle teve um pico por volta do $90^{\circ}$ dia de vida $(23,4 \%, \mathrm{n}=15, \mathrm{p}<0,05)$, seguido por outro maior $(34,4 \%, \mathrm{n}=22)$ no $120^{\circ}$ dia $(\mathrm{p}<0,01)$.

\section{Tabela 6}

Razões de chances não-ajustadas e ajustadas e seus respectivos intervalos de confiança $95 \%$, comparando casos de Diabetes Mellitus e controles. Campina Grande, PB, 2000.

\begin{tabular}{|c|c|c|c|}
\hline Características & RC (IC95\%) & RCajust (IC95\%) & $p^{*}$ \\
\hline Amamentação exclusiva até 4 meses & & & 0,01 \\
\hline Sim & 1,00 & 1,00 & \\
\hline Não & $3,17 \quad(1,26-7,93)$ & $4,09(1,19-14,04)$ & \\
\hline Escolaridade materna** & & & 0,01 \\
\hline 0 (Analfabeta) & 1,00 & 1,00 & \\
\hline Até 4 & $0,33(0,03-3,20)$ & $0,11(<0,01-1,93)$ & \\
\hline Até 8 & $0,06(<0,01-1,00)$ & $0,02(<0,01-0,69)$ & \\
\hline Até 11 & $0,20 \quad(0,01-3,66)$ & $0,07(<0,01-2,82)$ & \\
\hline maior que 11 & $0,58 \quad(0,02-15,3)$ & $0,24(<0,01-11,9)$ & \\
\hline Renda familiar $* * *$ & $0,66(0,44-1,01)$ & $0,68 \quad(0,41-1,13)$ & 0,13 \\
\hline Peso ao nascer*** & $1,00(0,99-1,00)$ & $0,99(0,99-1,00)$ & 0,65 \\
\hline História familiar de diabetes & & & 0,07 \\
\hline Não & 1,00 & 1,00 & \\
\hline Sim & $2,22(1,01-4,92)$ & $2,57 \quad(0,85-7,73)$ & \\
\hline
\end{tabular}

* Teste da razão de verossimilhança; ** Em anos de estudo; *** Variável contínua 


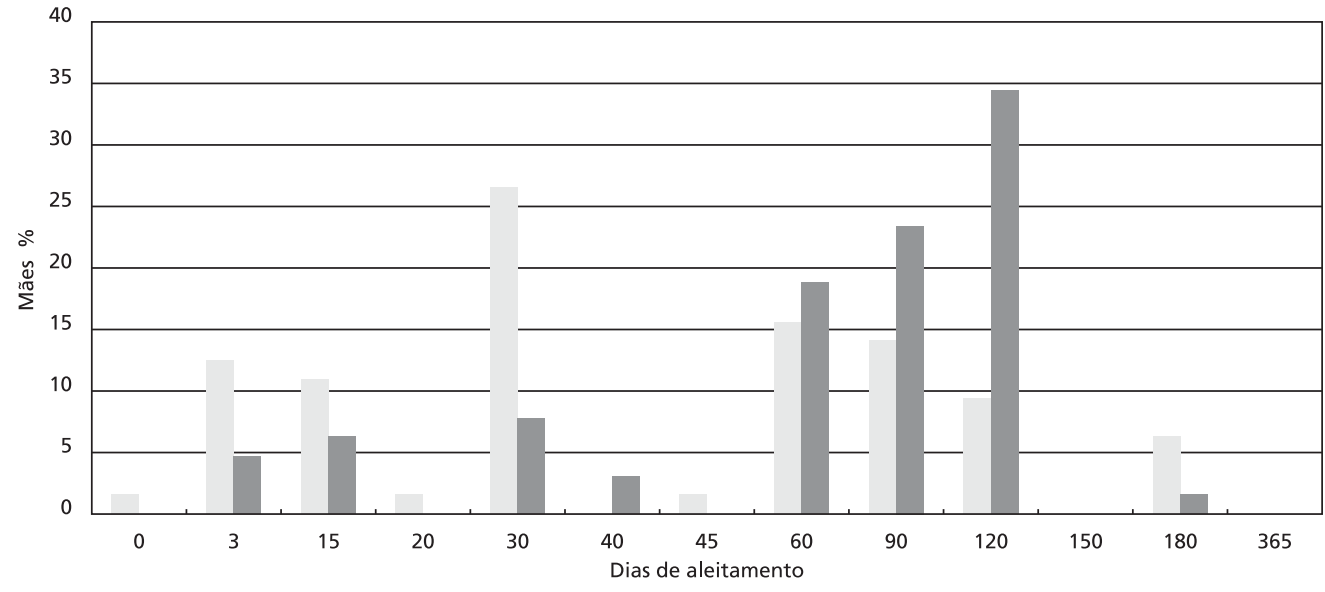

\section{Discussão}

A incidência do diabetes tipo 1 em Campina Grande foi estimada em 1,8/100.000 habitantes/ano, através de um estudo realizado pela Organização Mundial da Saúde (OMS), dentro do projeto Diabetes Mondiale (DIAMOND), que teve por objetivo estudar a incidência da doença em todo o mundo. A pesquisa não indicou a ocorrência do diabetes em pacientes de raça negra, amarela ou indígena. 5 Resultados semelhantes foram encontrados neste estudo em relação a essa característica. Em relação ao gênero, observou-se uma similaridade da amostra com outros estudos, que mostram que o diabetes tipo 1 atinge igualmente homens e mulheres. 18

Mijac et al. ${ }^{19}$ alertam para o fato de que mães mais idosas têm uma maior probabilidade de gerar filhos com problemas genéticos, como o diabetes. Nesta pesquisa entretanto, não houve diferenças em relação à idade materna na época do nascimento dos indivíduos. O número de mães primíparas foi maior no grupo de diabéticos, contrariando os dados citados na literatura, pois outra hipótese para o aparecimento do Diabetes Mellitus tipo 1 seria o fato da mãe ser multípara: após sucessivos partos, a probabilidade de ocorrer problemas genéticos com os filhos aumentaria. 19 Neste aspecto, é importante considerar os resultados do estudo realizado por Rivera e Ferreira20 com mães puérperas em Campina Grande. Os au- tores observaram que as mães primíparas eram as que apresentavam maior dificuldade para amamentar, fato que poderia explicar a contradição dos nossos resultados com a informação da literatura.

Vários estudos mostram que, quanto maior a escolaridade materna, maior o tempo de amamentação exclusiva.21,22 Venâncio e Monteiro,23 ao comentarem o aumento da proporção de crianças amamentadas no Brasil entre 1975 e 1989, chamam a atenção para o fato de que esse foi mais expressivo entre mulheres de maior escolaridade. Nesse grupo, a duração da amamentação mais que triplicou, no período citado (aumentou 346\%, passando de 46 para 159 dias). Já entre as mães de menor escolaridade, o aumento foi mais discreto, em torno de $38 \%$. A distribuição das mães dos entrevistados segundo a escolaridade, confirma o que revela a literatura, pois as mães do grupo controle tiveram um maior tempo de escolaridade, quando comparadas ao grupo de casos.

De acordo com a literatura, o pico de incidência do Diabetes Mellitus tipo 1 ocorre na faixa etária de 10 a 14 anos. ${ }^{24} \mathrm{Na}$ Venezuela, Mijac et al.,19 ao pesquisarem o papel dos fatores ambientais no desenvolvimento do Diabetes Mellitus tipo 1 em crianças, encontraram uma idade média de eclosão dessa doença em torno de 8,3 anos.

Em Pernambuco, Araújo et al. 25 descreveram o perfil epidemiológico dos pacientes com Diabetes 
Mellitus tipo 1 diagnosticados no Instituto Materno Infantil de Pernambuco (IMIP) e encontraram uma frequiência de eclosão da doença significativamente maior na faixa de cinco a nove anos $(37,1 \%)$, em comparação com as demais faixas etárias, enquanto a média de eclosão do diabetes no presente estudo foi de 9,1 anos.

Mijac et al. 19 observaram que uma maior proporção de pacientes diabéticos tipo 1 tinha antecedentes familiares de Diabetes Mellitus em relação ao grupo controle. A maior parte dos familiares (77,53\%) era portadora de diabetes tipo 2 .

Neste estudo, o grupo de casos mostrou, na análise univariada, uma associação positiva com história familiar de diabetes, no entanto, na análise de regressão logística a variável não apresenta associação. Gimeno e Souza24 chamam a atenção para o fato de que mesmo com antecedentes genéticos, o processo auto-imune que caracteriza o Diabetes Mellitus tipo 1 é desencadeado a partir de algum fator externo ou interno que induz o organismo a produzir anticorpos contra as células $\beta$ das ilhotas de Langerhans no pâncreas.

Venâncio e Monteiro,23 ao analisarem a tendência da amamentação na região Nordeste no ano de 1989, encontraram uma mediana de 157 dias (amamentação complementada). Este trabalho mostra que o tempo da amamentação materna complementada foi maior no grupo controle.

Em relação à amamentação materna exclusiva, a literatura mostra que há uma grande variabilidade. As cidades de Florianópolis, SC, Campinas, SP, e Feira de Santana, BA, apresentaram uma duração mediana em torno de 60 dias, enquanto que em cidades como o Rio de Janeiro essa foi estimada em 13 dias. 26 Também em relação a essa modalidade de amamentação, o grupo controle deste estudo obteve um desempenho melhor do que o grupo de casos, fato que reforça a hipótese de que um maior tempo de amamentação materna exclusiva protege o indivíduo contra o diabetes.

Neste estudo, 39\% das mães dos diabéticos realizaram parto cesariano, o que pode ter dificultado o início e conseqüente manutenção da amamentação. As demais mães realizaram parto normal. Entre as mães do grupo controle, $72 \%$ realizaram partos normais e $28 \%$ partos cesários, o que parece corroborar a hipótese de que o parto normal facilita o início e a manutenção da amamentação. ${ }^{20}$

A amamentação exclusiva é interrompida muito cedo, na maioria das cidades brasileiras, permanecendo muito aquém das recomendações da OMS e do Fundo das Nações Unidas para a Infância (UNICEF)27 e da política brasileira, que preconizam a amamentação exclusiva para todas as crianças até os quatro ou seis meses de idade. 28

Kitoko et al. 26 analisaram a prática da amamentação exclusiva em crianças menores de quatro meses em Florianópolis, SC, e em João Pessoa, PB, encontrando percentuais de $46,3 \%$ e $23,9 \%$, respectivamente. Nesta pesquisa, por outro lado, observaram-se percentuais de $15,6 \%$ para o grupo de casos e $35,9 \%$ para o grupo controle.

É importante observar que um primeiro nível de controle de possíveis elementos confundidores como o sexo, idade, cor e fatores ambientais foi realizado por meio do desenho do estudo. Após todos os ajustes, verificou-se que houve uma associação estatisticamente significante entre a ocorrência de Diabetes Mellitus tipo 1 nos indivíduos estudados e a exposição precoce ao leite de vaca (razão de chances $=4,09$ ) indicando que os indivíduos expostos têm quatro vezes mais chance de desenvolver o Diabetes tipo 1. Resultados semelhantes foram encontrados em São Paulo, por Gimeno e Souza. 29

Deve-se observar que uma das limitações dos estudos de caso-controle é o viés de recordação. No entanto, como observaram Kostraba et al. 17 é pouco provável a ocorrência de viés diferencial de memória entre as mães das crianças diabéticas, pois raramente são inquiridas sobre as práticas alimentares e, desta forma, não associam o aparecimento da doença com esse fato. Além disso, relatam os autores, tem sido encontrada boa reprodutibilidade das informações referentes à alimentação da criança, nos primeiros dias de vida, por diferentes pesquisadores. Tal fato sugere que, apesar das dificuldades para a determinação precisa do período crítico de risco, é pouco provável a existência de viés nos resultados encontrados nas diferentes pesquisas.

\section{Conclusões}

Os resultados encontrados mostram a necessidade de uma revisão política séria no sistema de saúde, criando equipes multidisciplinares que possam atuar junto à gestante e à mãe que amamenta, incentivando a prática do aleitamento materno exclusivo até os quatro ou seis meses de idade e o prolongamento do aleitamento materno pelo menos até os 12 meses. $\mathrm{O}$ UNICEF30 recomenda o aleitamento materno exclusivo nos primeiros seis meses e sua manutenção por dois anos ou mais. No entanto, percebe-se também que o setor saúde deve levar em conta o papel da sociedade quanto ao apoio à mulher que amamenta e trabalha fora do lar, para que ela possa ter melhores condições para amamentar seus filhos. 
Um outro aspecto relevante é a educação materna. Segundo o UNICEF, 30 melhores práticas de aleitamento materno e redução de alimentação artificial poderiam salvar 1,5 milhão de crianças por ano. Dados atuais mostram que cerca de dois terços dos 876 milhões de adultos analfabetos em todo o mundo são mulheres e que o aumento da escolaridade materna está diretamente vinculada à melhoria da alimentação de sua família, incluindo um maior tempo de amamentação materna exclusiva para seus filhos. ${ }^{31,32}$

Diante dos resultados encontrados, nesta e em outras pesquisas, torna-se evidente a importância da realização de estudos complementares para avaliar a influência da introdução precoce do leite de vaca na alimentação humana, sobretudo na ausência de aleitamento materno. O desenvolvimento de estudos prospectivos, tais como o que está sendo coordenado por Äkerblom et al., 33 talvez possa, nos próximos anos, esclarecer alguns aspectos sobre a relação desse fator de risco e o desenvolvimento do Diabetes Mellitus tipo 1.

Como forma de prevenir o aparecimento do Diabetes Mellitus tipo 1, além de várias outras enfermidades, sugere-se a amamentação exclusiva ao seio pelo menos durante quatro meses, evitando-se a introdução precoce, na alimentação infantil, do leite de vaca e seus derivados.

\section{Referências}

1. Zachrisson I, Brismar K, Wallensteen M, Dahlquest G. Determinants of growth in diabetic pubertal subjects. Diabetes Care 1997; 20: 1261-5.

2. Cardoso MAA. Epidemiologia das doenças crônico-degenerativas: hipertensão arterial e Diabetes mellitus. In: Guimarães AF, Medeiros JLA, Brasileiro MCE. Olhar multifacetado na saúde. Campina Grande: EDUEP; 1999. p. 267-79.

3. Araújo IML. Avaliação do efeito hipoglicemiante da Citrullus vulgaris scharad (melancia) em indivíduos diabéticos tipo 2 e normais [dissertação mestrado]. João Pessoa: Departamento de Nutrição, Centro de Ciências da Saúde da Universidade Federal da Paraíba; 1999.

4. American Diabetes Association. Report of the Expert Committee on the diagnosis and classification of Diabetes Mellitus. Diabetes Care 1999; 22 Suppl 1: 5-19.

5. Campos JJB, Almeida HGG, Iochida LC, Franco LJ. Incidência de Diabetes Melliuts insulino dependente (Tipo 1) na cidade de Londrina, PR, Brasil. Arq Bras Endocrinol Metabol 1998, 42: 36-44.

6. Karlsson MGE, Ludvigsson J. The ABBOS-peptide form bovine serum albumin causes in IFN-g and IL-4 mRNA response in lymphocytes from children with recent onset of type 1 diabetes. Diabetes Res Clin Prac 2000; 47: 199-207.

7. Pérez-Bravo F, Calvillán MC, Santos JLM, Carrasco EP. Incidence of type I (Insulin-dependent) Diabetes Mellitus in Santiago, Chile: the role of immunogenetic and environmental factors. Rev Med Chile 1996; 124: 1177-86.

8. Fukushima Y, Kawata Y, Onda T, Kitagawa M. Consumption of cow milk and egg by lactating womem and the presence of b-lactoglobulin and ovalbumin in breast milk. Am J Clin Nutr 1997; 65: 30-5.

9. Paronen J. Effect of cow's milk exposure and maternal type 1 diabetes on cellular and humoral immunization to dietary insulin in infants at genetic risk for type 1 diabetes. Diabetes 2000; 49: 1657-65.
10. Atkinson MA. Lack of immunity to bovine serum albumin in insulin-dependent Diabetes Mellitus. New Engl J Med 1994; 330: 1853-8.

11. Blanchardo JF, Dean H, Anderson K, Wadja A, Ludwig S, Depew N. Incidence and prevalence of diabetes in children aged 0-14 years in Manitoba, Canadá: 1985-1993. Diabetes Care 1997; 20: 512-5.

12. Collado-Mesa F, Díaz-Díaz O. Frequency and duration of breast-feeding in Cuban children with type 1 Diabetes Mellitus (DM). Rev Bras Epidemiol 1998; 1: 294-7.

13. Dewey KG, Cohen RJ, Brown KH, Rivera LL. Age of introduction of complementary foods and growth of term, low-birth-weigth, breast-fed infants: a randomized intervention study in Honduras. Am J Clin Nutr 1999; 69: 679-86.

14. Pardini VC, Vieira JGH, Miranda W, Ferreira SRG, Velho G, Russo EMK. Antibodies to bovine serum albumin in Brazilian children and young adults with IDDM. Diabetes Care 1996; 19: 126-9.

15. Mckiben DH, Dosch HM. Cow's milk, bovine serum albumin, and IDDM: Can we settle the controversies? Diabetes Care 1997; 20: 897-901.

16. Barros FC, Victora CG. Epidemiologia da saúde infantil: um manual para diagnósticos comunitários. São Paulo: Hucitec; 1991.

17. Kostraba JN, Cruiekshanks J, Lawer-Heavner J, Owada GF. Early exposure to cow's milk and solid food in infancy, genetic predisposition and risk of IDDM. Diabetes 1993; 42: 288-95.

18. Toth EL, Lee KC, Couch RM, Martin LF. High incidence of IDDM over 6 years in Edmonton, Alberta, Canadá. Diabetes Care 1997; 20: 311-2.

19. Mijac V, Arrieta J, Mendt C, Valbuena H, Ryder E. Papel de los factores ambientales en el desarrolo de la Diabetes Mellitus insulino dependiente (DMID) em niños venezolanos. Invest Clin 1995; 36: 73-82.

20. Rivera MAA, Ferreira FN. Causas e conseqüências do des- 
mame em crianças menores de um ano de idade na cidade de Campina Grande, PB. In: Anais do VII Encontro de Iniciação Científica; 2000 nov 21-22; Campina Grande, Paraíba. Resumos... Campina Grande: Universidade Estadual da Paraíba; 2000. p. 70.

21. Rea MF, Cukier R. Razões de desmame e de introdução da mamadeira: uma abordagem alternativa para seu estudo. Rev Saúde Pública 1988; 22: 184-91.

22. Soares NT, Guimarães ARP, Sampaio HAC, Almeida PC, Coelho RR. Padrão alimentar de lactentes residentes em áreas periféricas de Fortaleza. Rev Nutr 2000; 13: 16776

23. Venancio SI, Monteiro CA. A tendência da prática da amamentação no Brasil nas décadas de 70 e 80 . Rev Bras Epidemiol 1998; 1: 40-9.

24. Gimeno SGA, Souza JMP. Amamentação ao seio, amamentação com leite de vaca e o Diabetes Mellitus tipo 1: examinado as evidências. Rev Bras Epidemiol 1998; 1: 4-13.

25. Araújo J, Soares T, Ferreira A, Menezes D, Correia JB Gomes S. Perfil epidemiológico dos pacientes com Diabetes Mellitus tipo 1 diagnosticados no Instituto Materno Infantil de Pernambuco, IMIP. Rev IMIP 2000; 14: 163-7.

26. Kitoko PM, Réa MF, Venancio SI, Vasconcelos ACCP, Santos EKA, Monteiro CA. Situação do aleitamento materno em duas capitais brasileiras: uma análise comparada. Cad Saúde Pública 2000; 16: 1111-9.
27. UNICEF (Fundo das Nações Unidas para a Infância). Declaração de Innocenti sobre a proteção, promoção e apoio ao aleitamento materno. New York: O Fundo; 1990.

28. INAN (Instituto Nacional de Alimentação e Nutrição), UNICEF (Fundo das Nações Unidas para a Infância). Aleitamento materno e o município. Rio de Janeiro: Coronário; 1995.

29. Gimeno SGA, Souza JMP. IDDM and milk consuption: a case-control study in São Paulo, Brasil. Diabetes Care 1997; 20: 1256-60.

30. UNICEF (Fundo das Nações Unidas para a Infância). Situação mundial da infância: 2001. New York: O Fundo; 2001.

31. Batista Filho M. Cenário nutricional do Brasil: situação das crianças brasileiras no período 1990/1999. In: Rivera MAA, Costa MJC. A nova nutrição. João Pessoa: Ed. Universidade Federal da Paraíba; 2000. p. 15-26.

32. Borges ALV, Lucca A, Fisberg RM, Szarfarc SC. Leite materno: recomendações $\mathrm{x}$ consumo de energia. Cad Nutr 1998; 15: 25-32

33. Äkerblom HK, Savilahti E, Saukkonen TT, Smith GH. The case of elimination of cow's milk in early infancy in the prevention of type 1 diabetes: the Finnish experience. Diabetes Metabol 1998; 9: 269-78.

Recebido em 31 de julho de 2002

Versão final apresentada em 29 de abril de 2003

Aprovado em 30 de julho de 2003 